\title{
Preejection Period as a Sympathetic Activity Index: a Role of Confounding Factors
}

\author{
J. KROHOVA ${ }^{1,2,3}$, B. CZIPPELOVA ${ }^{1,2}$, Z. TURIANIKOVA ${ }^{1,2}$, Z. LAZAROVA $^{1,2}$, \\ I. TONHAJZEROVA ${ }^{1,2}$, M. JAVORKA ${ }^{1,2}$
}

${ }^{1}$ Department of Physiology, Jessenius Faculty of Medicine in Martin, Comenius University in Bratislava, Martin, Slovakia, ${ }^{2}$ Biomedical Center Martin, Jessenius Faculty of Medicine in Martin, Comenius University in Bratislava, Martin, Slovakia, ${ }^{3}$ Department of Cybernetics and Biomedical Engineering, VSB - Technical University of Ostrava, Ostrava, Czech Republic

Received February 3, 2017

Accepted February 26, 2017

\section{Summary}

In previous studies, one of the systolic time intervals preejection period (PEP) - was used as an index of sympathetic activity reflecting the cardiac contractility. However, PEP could be also influenced by several other cardiovascular variables including preload, afterload and diastolic blood pressure (DBP). The aim of this study was to assess the behavior of the PEP together with other potentially confounding cardiovascular system characteristics in healthy humans during mental and orthostatic stress (head-up tilt test-HUT). Forty-nine healthy volunteers (28 females, 21 males, mean age 18.6 years ( $S D=1.8$ years)) participated in the study. We recorded finger arterial blood pressure by volume-clamp method (Finometer Pro, FMS, Netherlands), PEP, thoracic fluid content (TFC) - a measure of preload, and cardiac output (CO) by impedance cardiography (CardioScreen $^{\circledR}$ 2000, Medis, Germany). Systemic vascular resistance (SVR) - a measure of afterload - was calculated as a ratio of mean arterial pressure and $\mathrm{CO}$. We observed that during HUT, an expected decrease in TFC was accompanied by an increase of PEP, an increase of SVR and no significant change in DBP. During mental stress, we observed a decrease of PEP and an increase of TFC, SVR and DBP. Correlating a change in assessed measures (delta values) between mental stress and previous supine rest, we found that $\triangle \mathrm{PEP}$ correlated negatively with $\triangle \mathrm{CO}$ and positively with $\triangle \mathrm{SVR}$. In orthostasis, no significant correlation between $\triangle \mathrm{PEP}$ and $\triangle \mathrm{DBP}, \triangle \mathrm{TFC}, \triangle \mathrm{CO}, \triangle \mathrm{MBP}$ or $\triangle \mathrm{SVR}$ was found. We conclude that despite an expected increase of sympathetic activity during both challenges, PEP behaved differently indicating an effect of other confounding factors. To interpret PEP values properly, we recommend simultaneously to measure other variables influencing this cardiovascular measure.

\section{Key words}

Preejection period - Impedance cardiography - Head-up tilt • Mental stress • Thoracic fluid content • Systemic vascular resistance

\section{Corresponding author}

J. Krohova, Department of Physiology, Jessenius Faculty of Medicine in Martin, Comenius University in Bratislava, Mala Hora 4C, 03601 Martin, Slovakia. E-mail: Jana.Krohova@jfmed.uniba.sk

\section{Introduction}

Preejection period (PEP) belongs to three basic systolic time intervals (together with left ventricular ejection time - LVET and total electromechanical systole duration - $\mathrm{QS}_{2}$ ). PEP is significantly affected by the heart inotropy and is commonly regarded as an index of cardiac sympathetic ( $\beta$-adrenergic) activity (Larkin and Kasprowicz 1986, Cacioppo et al. 1994a, Schächinger et al. 2001, Parry et al. 2015). PEP is the sum of the electromechanical delay (from the $Q$ wave on electrocardiogram to the onset of pressure rise in the left ventricle) and the duration of the isovolumic contraction (rapid rise of the left ventricular pressure up to the level of the diastolic aortic pressure, when aortic valve opens-Fig. 1). While the electromechanical delay in healthy human takes $30-40 \mathrm{msec}$ and is only minimally affected by different physiological and pathophysiological states (Lewis et al. 1977, Afonso et al. 2009), the duration 
of isometric contraction is more variable. The duration of the isometric contraction phase dominantly influencing the duration of PEP is considered to depend primarily on cardiac contractility but it is also significantly influenced by cardiac preload (Lewis et al. 1977, Buch et al. 1980, Cacioppo et al. 1994a, Beauchaine et al. 2013) and afterload (Hodges et al. 2010). An increase in cardiac preload leads to increased contraction strength via FrankStarling mechanism and subsequently to a decrease of
PEP. In contrast, increased systemic vascular resistance prolongs the PEP by increased cardiac afterload (Sherwood et al. 1990). Additionally, changes in diastolic blood pressure (DBP) could also have an impact on the duration of the PEP (Fig. 1) (Lewis et al. 1974). Taken together, when using PEP as an index of cardiac sympathetic activity influencing ventricular contractility it is important to consider preload, afterload and DBP as potential confounding factors (Fig. 1).

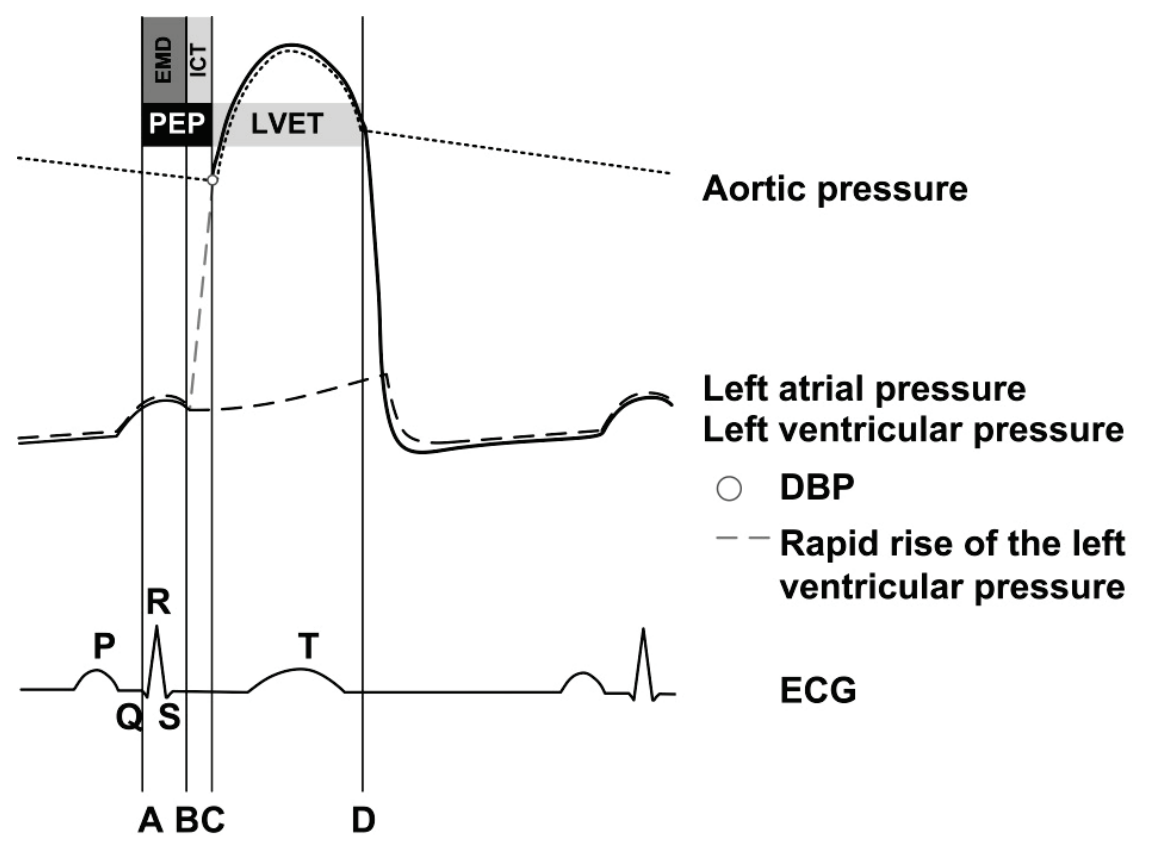

Fig. 1. Components of the PEP (Katz 2011). Theoretically, when diastolic blood pressure (DBP) increases, the aortic valve opening (point $\mathrm{C}$ ) is reached later and PEP could be prolonged. EMD denotes the electromechanical delay (A-B), ICT denotes isovolumic contraction time (B-C); A, B, C and D denote $\mathrm{Q}$ wave onset, closing of the mitral valve, opening of the aortic valve, and closing of the aortic valve, respectively.

In previous studies the PEP was used as an index of sympathetic activity during different states and in different study groups. Although the influence of confounding factors on PEP is assumed, the behavior of the confounding factors (preload, afterload and DBP) together with PEP during various physiological conditions in healthy subjects was only rarely studied.

Therefore, the aim of this study was to assess the changes of the PEP together with other cardiovascular system characteristics during mental and orthostatic stress in healthy humans.

\section{Methods}

\section{Subjects}

In total, 49 healthy volunteers (28 females, 21 males) with a mean age of 18.6 years $(\mathrm{SD}=1.8$ year, range $15.8-22.6$ years) participated in this study. Subjects were instructed not to use substances influencing autonomic nervous system or cardiovascular system activity. Female subjects were examined in the proliferative phase of the menstrual cycle. All procedures were approved by Ethical Committee of the Jessenius Faculty of Medicine, Comenius University and all participants signed a written informed consent.

\section{Data acquisition}

We recorded finger arterial blood pressure (DBP and mean arterial pressure (MBP)) by volume-clamp method (Finometer Pro, FMS, Netherlands). We used reconstructed brachial arterial pressure applying return-to-flow calibration to improve the accuracy of blood pressure measurement. MBP was calculated as the true integrated mean pressure between the current and the next upstroke and DBP as the low pressure just before the current upstroke. The PEP, thoracic fluid content (TFC) a measure of preload, and cardiac output (CO) were recorded by impedance cardiography (CardioScreen ${ }^{\circledR}$ 2000, Medis, Germany). Systemic vascular resistance (SVR) - a measure of afterload - was calculated as a ratio 
of mean arterial pressure and $\mathrm{CO}$, assuming zero venous pressure at the right atrium (Krzesiński et al. 2012, Krzesiński et al. 2016, Lasater and Von Rueden 2003, Sodolski and Kutarski 2007, Xiajuan et al. 2013). The duration of the PEP was defined as the time interval between R peak of the ECG and the B point of $\mathrm{dZ} / \mathrm{dt}$ of the ICG and TFC was calculated from the base impedance $Z_{0}\left(\mathrm{TFC}=1,000 / \mathrm{Z}_{0}\right)$.

\section{Study protocol}

During the whole measurement, the volunteers were asked to avoid disturbing movements and speaking. They were positioned on the tilt table with the feet in contact with the footboard at the end of the table and restraining strap was secured at the thigh level to provide subject support and safety. The study protocol consisted of four phases: supine rest (15 min), head-up tilt (HUT, the subject was tilted to 45 degrees on the motor driven tilt table for $8 \mathrm{~min}$ to evoke mild orthostatic stress), supine recovery $(10 \mathrm{~min})$, followed by mental arithmetic task (MA) in the supine position for $6 \mathrm{~min}$. During the MA task the subject was instructed to sum up three-digit numbers (until one-digit number was reached) displayed on the ceiling of the examination room by a data projector. After deciding if the final one-digit number was odd or even, the subject had to click by computer mouse on the corresponding push button projected on the ceiling. During the mental arithmetic task, the subject was disturbed by the rhythmic sound of a metronome and instructed to perform the mental arithmetic task as quickly as possible with a minimal error rate.

\section{Data analysis}

To avoid transient changes, we have extracted following 300 beats lasting segments from the original recordings for data analysis: for the first phase the analysed segment started $8 \mathrm{~min}$ after the beginning of this phase, for the second phase $3 \mathrm{~min}$ after the change of the position, for the third phase $7 \mathrm{~min}$ before starting the MA task and for the fourth phase 2 min after starting of this phase. We have calculated median values of beat-tobeat recorded cardiovascular measures (PEP, TFC, SVR, and DBP) for each phase. As the next step, the change in median values (delta values: $\triangle \mathrm{PEP}, \triangle \mathrm{TFC}, \triangle \mathrm{SVR}$ and $\triangle \mathrm{DBP}$ ) as a response to HUT (a change from phase 1 to phase 2: median value from phase 2 minus median value from phase 1) and as a response to MA (a change from phase 3 to phase 4 : median value from phase 4 minus median value from phase 3 ) were calculated.

\section{Statistical analysis}

Due to non-normal distribution of the assessed variables, nonparametric tests were used for statistical analysis. A comparison between median values (median PEP, TFC, SVR and DBP) obtained from different phases (phase 2 vs. 1 and phase 4 vs. 3) was performed by Wilcoxon signed-rank test. The correlations between $\triangle \mathrm{PEP}$ and $\triangle \mathrm{TFC}, \triangle \mathrm{SVR}, \triangle \mathrm{DBP}$, were calculated separately for HUT and MA using Spearman correlation analysis. The results were considered statistically significant at $\mathrm{P}<0.05$. The statistical analysis was performed using statistical software SYSTAT 13 (Systat Software Inc., USA).

\section{Results}

\section{Response to orthostasis}

While PEP and SVR during HUT were significantly higher than during supine rest (for both $\mathrm{P}<0.0001$ ), TFC, MBP and CO were significantly lower compared to preceding supine rest phase $(\mathrm{P}<0.0001$ for each). No significant change in DBP was observed during HUT compared to previous phase ( $\mathrm{P}=0.5343)$. Correlating a change in analyzed measures (delta values) between HUT and previous supine rest we found no significant correlation between $\triangle \mathrm{PEP}$ and $\triangle \mathrm{TFC}$ $(\mathrm{rho}=-0.027, \mathrm{P}=0.854), \Delta \mathrm{SVR} \quad(\mathrm{rho}=0.212, \mathrm{P}=0.143)$, $\triangle \mathrm{DBP} \quad(\mathrm{rho}=0.003, \quad \mathrm{P}=0.984), \quad \Delta \mathrm{MBP} \quad(\mathrm{rho}=-0.143$, $\mathrm{P}=0.327)$ or $\Delta \mathrm{CO}(\mathrm{rho}=-0.216, \mathrm{P}=0.136)$ (Fig. 2, 3).

\section{Response to mental stress}

PEP significantly decreased compared to preceding supine recovery during MA $(\mathrm{P}=0.0025)$, whileas TFC, SVR, MBP, DBP and CO significantly increased $(\mathrm{P} \leq 0.0022)$. Analyzing the correlations between responses to mental task, we found a significant negative correlation between $\triangle \mathrm{PEP}$ and $\triangle \mathrm{CO} \quad(\mathrm{rho}=-0.526$, $\mathrm{P}=0.0001)$ and a significant positive correlation between $\triangle \mathrm{PEP}$ and $\triangle \mathrm{SVR}(\mathrm{rho}=0.333, \mathrm{P}=0.019)$. No significant correlation between $\triangle \mathrm{PEP}$ and $\triangle \mathrm{TFC} \quad(\mathrm{rho}=0.115$, $\mathrm{P}=0.432), \quad \Delta \mathrm{DBP} \quad(\mathrm{rho}=-0.126, \quad \mathrm{P}=0.387) \quad$ or $\quad \Delta \mathrm{MBP}$ (rho $=-0.242, \mathrm{P}=0.094$ ) was found.

\section{Discussion}

Despite an expected increase in cardiac sympathetic activity during both orthostatic test and cognitive load associated with mental arithmetics task, the changes in PEP were unequivocal: PEP increased 
during HUT but it decreased during MA. Our analysis revealed the important influence of other mechanisms on the PEP duration that should be taken into consideration when PEP is analysed and interpreted.

\section{Median PEP}

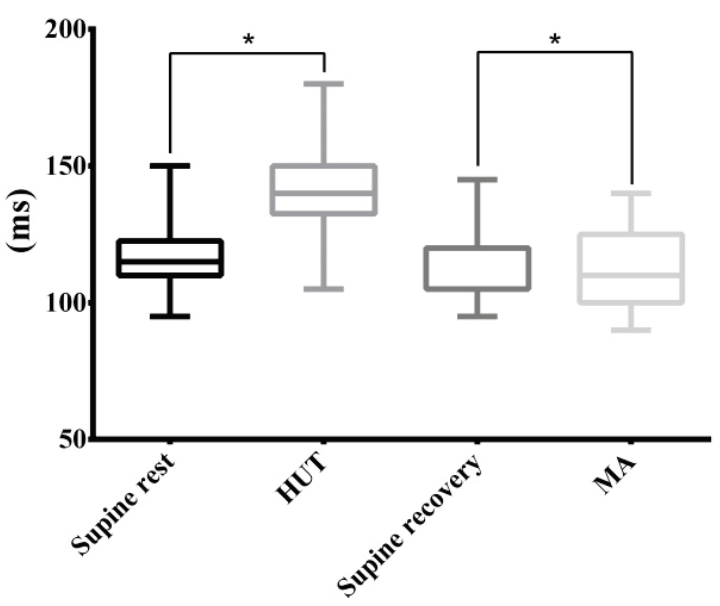

Median TFC

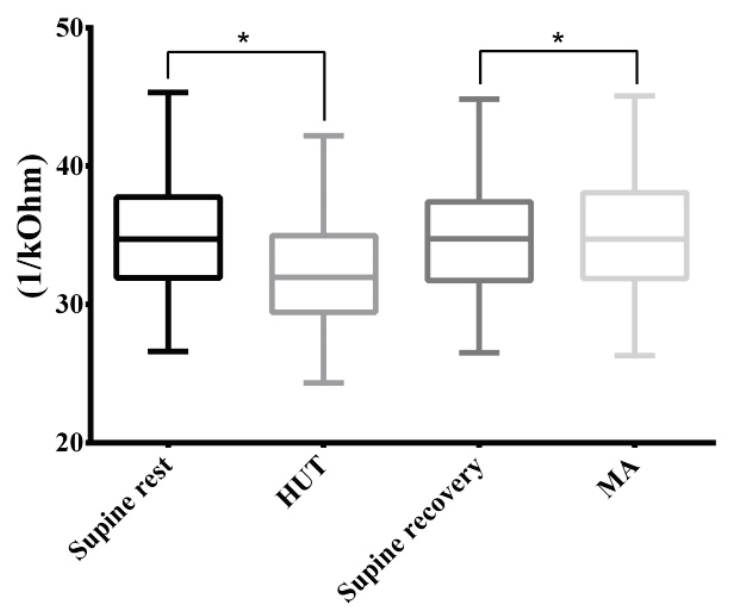

Median DBP

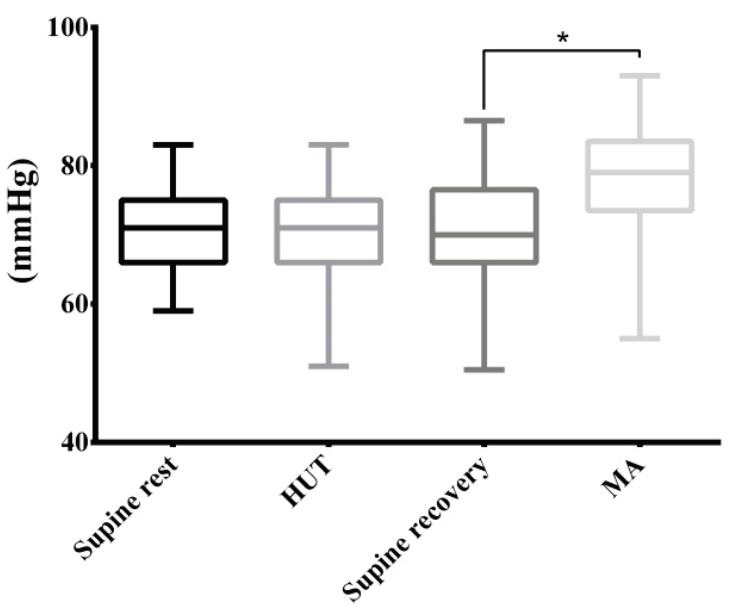

Median SVR

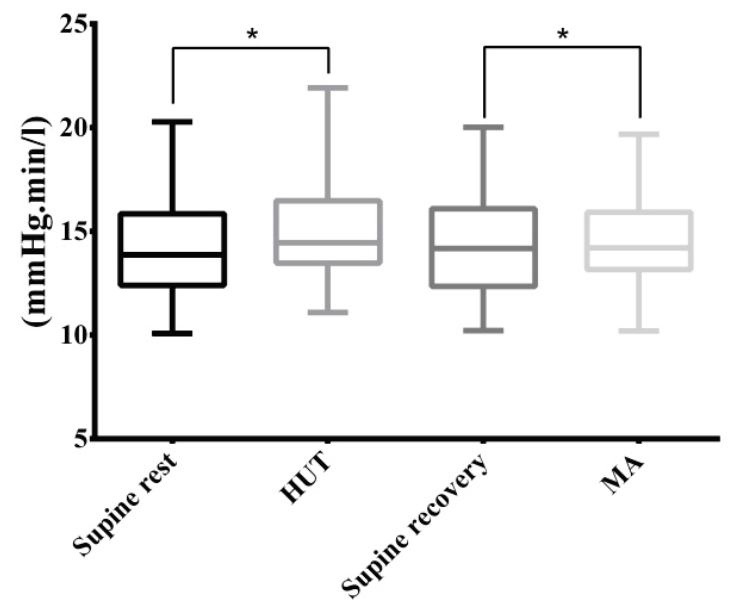

Fig. 2. Median values of PEP, DBP, TFC and SVR during four phases of study protocol. * denotes significant difference, PEP - preejection period, DBP - diastolic blood pressure, TFC - thoracic fluid content, SVR - systemic vascular resistance, HUT - head-up tilt, MA - mental arithmetic.
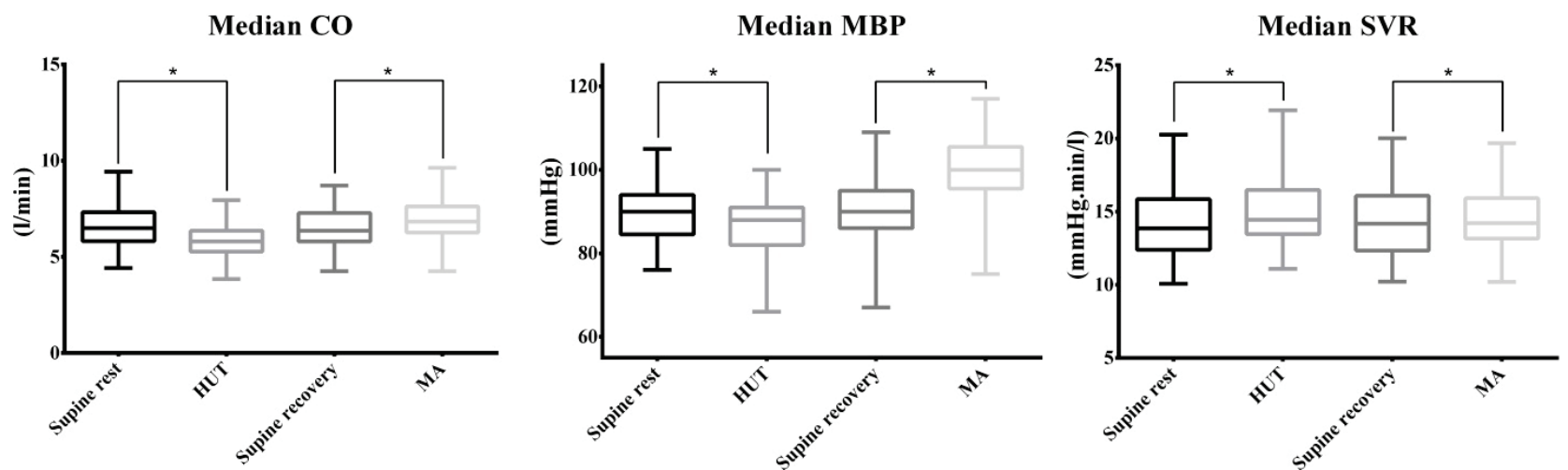

Fig. 3. Median values of $C O, M B P$, and SVR in four phases of study protocol. * denotes significant difference, CO - cardiac output, MBP - mean arterial pressure, SVR - systemic vascular resistance, HUT - head-up tilt, MA - mental arithmetic. 
The cardiac inotropy being importantly influenced by the positive inotropic effect of the sympathetic branch of the autonomic nervous system can significantly influence the duration of PEP. Therefore, PEP has been proposed as a promising index of the cardiac sympathetic activity with a potentially important diagnostic and prognostic information value (Newlin and Levenson 1979). In a series of studies conducted over the last four decades, it was found that the duration of PEP is modified by a variety of physiological and pathological conditions. Factors prolonging the PEP include age, preload reduction, negative inotropic agents, heart failure and left bundle branch block. The shortening, on the other hand, occurs during exercise, emotional stress, as a response to positive inotropic agents, in aortic valve diseases, and acute hypoxemia (Lewis et al. 1977, Garrard et al. 1970, van Lien et al. 2013, Mensah-Brown et al. 2010). In the study comparing various sympathetic activity related indexes the PEP overcome the LF/HF ratio from the heart rate variability analysis as an index of the cardiac sympathetic activity (Goedhart et al. 2008).

Our study was aimed on the assessment of the PEP changes together with other potentially confounding cardiovascular system characteristics in healthy humans during physical (HUT) and mental (MA) challenges. The major motivation to perform this study was to improve our understanding on the potential limitations to use PEP as an index of cardiac sympathetic activity. There are many studies evaluating the duration of PEP during different physiological (change in the body position from supine to sitting and active or passive orthostasis, cognitive tasks, cold-pressor test, aging, etc.) and pathological (patients with heart failure, hypertension, atrial fibrillation, coronary artery disease, preeclampsia, chronic renal failure, etc.) states together with other measures possibly influencing PEP (Garrard et al. 1970, Stafford et al. 1970, Carroll et al. 1991, Fahrenberg and Foerster 1991, Mezzacappa et al. 1999, Kelsey et al. 2000, Schächinger et al. 2001, Schneider et al. 2003, El-Dawlatly et al. 2005, Richter et al. 2009, Hodges et al. 2010, Oben et al. 2014, Cieslak et al. 2015). However, in only two previous studies (in patients with cardiac failure and in morbidly obese patients) the PEP was measured together with three major confounding cardiovascular variables (preload, afterload, DBP) (Packer et al. 2006, El-Dawlatly et al. 2005). The study focused on the assessment of the PEP changes during two different stress conditions (physical and cognitive challenge) together with other confounding parameters in healthy subjects is still missing.

The mechanisms of adaptation to orthostatic stress are well known. During orthostasis - in our study we used a passive orthostasis - HUT - venous pooling of the blood in the lower portion of human body leads to a decrease in cardiac preload causing a decreased ventricular filling (end-diastolic volume), stroke volume and cardiac output. An increased afterload due to peripheral vasoconstriction was also found during orthostatic challenge (Stafford et al. 1970, Chan et al. 2007, Cacioppo et al. 1994b, Bettencourt et al. 2008, Svacinova et al. 2015). During HUT, we observed a significant increase in PEP duration, together with a decreased cardiac preload (a decrease in TFC from ICG), increased SVR and only negligible change in DBP. The prolonged PEP as a response to HUT was consistently found in previous studies despite the assumed increase of the sympathetic activity to the heart (Chan et al. 2007, Lewis et al. 1977, Ovadia et al. 1995). Considering the observed increase in PEP during HUT in the context of other cardiovascular characteristics changes, a decreased preload (TFC) evoked either by orthostatic maneuver itself or related to the concomitant tachycardia (a decrease of preload associated with a shorter duration of diastole) and an increased afterload (SVR) should be taken into consideration. The decreased preload leads to a prolongation of PEP via a decreased strength of cardiac contraction mediated by Frank-Starling mechanism (a decrease in end-diastolic volume results in a decrease of the contraction strength). We assume that the contribution of both preload and afterload varies among individuals and therefore we did not found statistically significant correlations between a change in PEP ( $\triangle \mathrm{PEP}$ ) and $\triangle \mathrm{TFC}$ or $\triangle \mathrm{SVR}$ related to orthostasis in the whole analyzed group. The decreased strength of ventricular contraction (expressed also by a decreased MBP) together with an increased SVR (peripheral vasocontriction) leads to a decreased $\mathrm{CO}$ potentially resulting in an orthostatic syncope in susceptible persons, if compensatory mechanisms fail (Critchley et al. 1997, Brignole et al. 2001, Kanjwal et al. 2015).

During cognitive tasks, several more or less expressed changes occur: parasympathetic activity decrease and/or a sympathetic activity increase cause an increased heart rate (positive chronotropic effect), stronger contractions of the heart muscle (positive inotropic effect), vasoconstriction in the renal and splanchnic circulations and vasodilatation in skeletal 
muscles (Lindvall et al. 1991, Kuipers et al. 2008, Widjaja et al. 2015). Mental load in our study evoked by mental arithmetics changed SVR only mildly - a mild but significant increase in SVR could be attributed to the predominance of sympathetic nervous system mediated vasoconstriction in our study. Blood redistribution could be also responsible for a slight increase in TFC. Theoretically, an increase in SVR could itself lead to an increase in PEP, because higher afterload will prolongate preejection period by prolonging time needed to open the aortic valve without changes in contractility (Houtveen et al. 2005). However, in our study during MA an increase of SVR was associated with a decrease in PEP duration both reflecting an increase in sympathetic activity towards vasculature and heart. As can be seen from the positive correlation illustrated on Figure 4, in subjects with more expressed vasoconstriction (higher $\triangle \mathrm{SVR}$ ), a decrease in PEP ( $\triangle \mathrm{PEP})$ is not as prominent as in subjects in whom $\triangle \mathrm{SVR}$ was close to zero. We suggest that an expected decrease in PEP associated with sympathetic stimulation could be opposed by a concomitant increase in SVR.

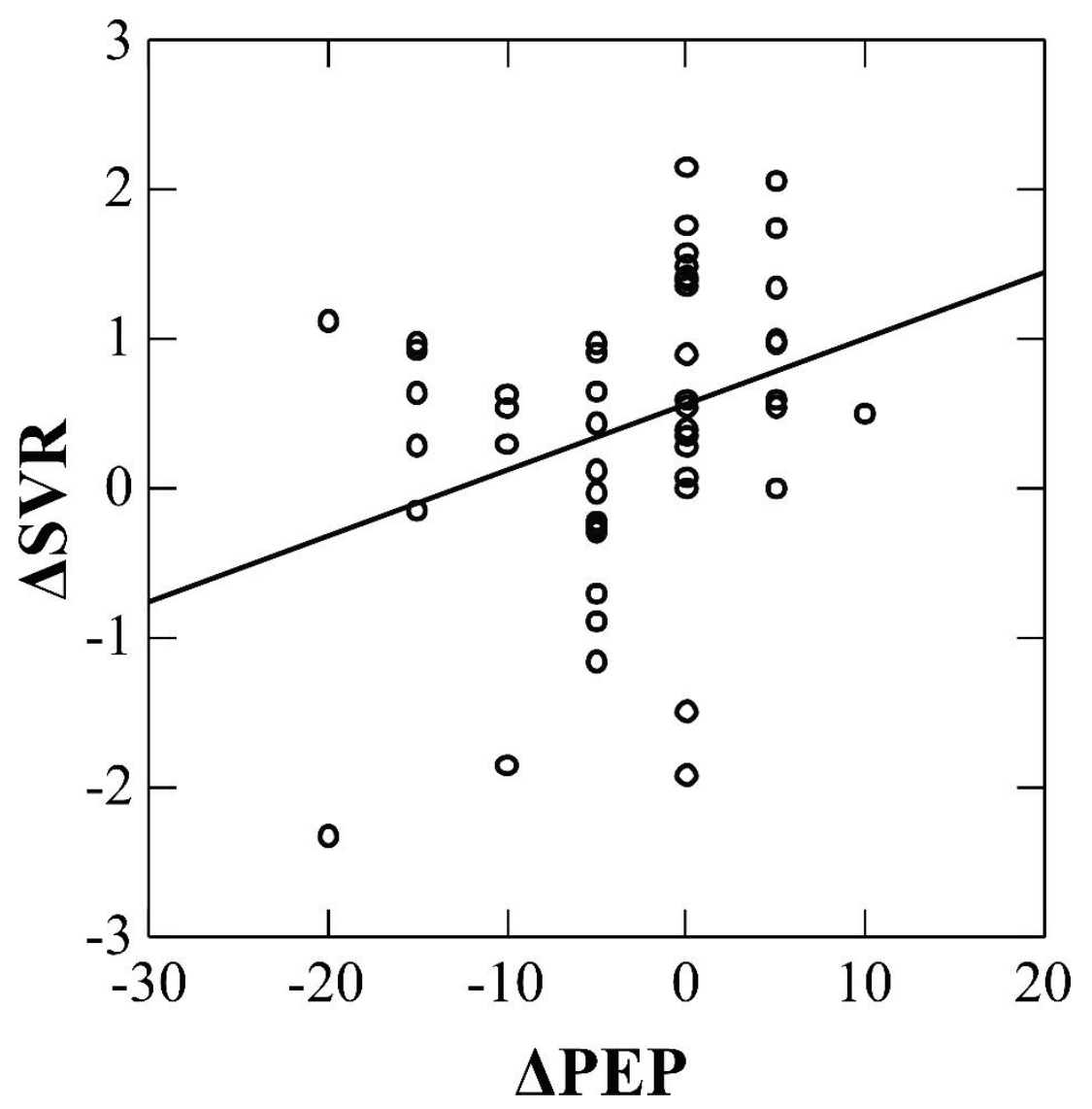

Fig. 4. Scatterplot between a change in preejection period ( $\triangle P E P$ ) and $\triangle$ SVR (a change in systemic vascular resistance). Each circle corresponds to one subject. In subjects with more expressed vasoconstriction (higher $\Delta S V R$ ), a decrease in PEP $(\triangle P E P)$ is not as prominent as in subjects in whom $\triangle S V R$ was close to zero.

An increased contractility expressed by a decreased PEP during MA is significantly correlated with an increase of cardiac output - this finding illustrates the involvement of the positive inotropic effect of sympathetic component of autonomic nervous system in an increase of $\mathrm{CO}$ during cognitive load. As can be seen from the scatterplot (Fig. 5), in subjects with less expressed decrease in PEP (with $\triangle \mathrm{PEP} \geq 0$ ), the $\mathrm{CO}$ increase was less expressed.

The shortening of PEP during mental stress was also found in previous studies (Harrell and Clark 1985, Carroll et al. 1991, Berntson et al. 1994, Kelsey et al. 2000, Schneider et al. 2003). Alternatively, a slightly but significantly increased preload (an increased TFC) could lead to a decrease of PEP observed during MA. However, this possible mechanism is not supported by a significant correlation between $\triangle \mathrm{PEP}$ and $\triangle \mathrm{TFC}$.

\section{Study limitations}

Our results and conclusions are based on the measurement of cardiovascular parameters by noninvasive methods potentially introducing a measurement error in our analysis. Our results can be influenced by the measurement error introduced by the non-invasive blood pressure measurement using photoplethysmographic volume clamp method. Validation studies conclude that 
although the absolute values of finger blood pressure can be distorted, the changes in the blood pressure can be measured with a good precision (Bogert and van Lieshout 2005, Imholz et al. 1998). To minimize the error in absolute values of blood pressure and to improve the accuracy of its measurement, reconstructed brachial arterial pressure using the return-to-flow calibration was applied in our study.

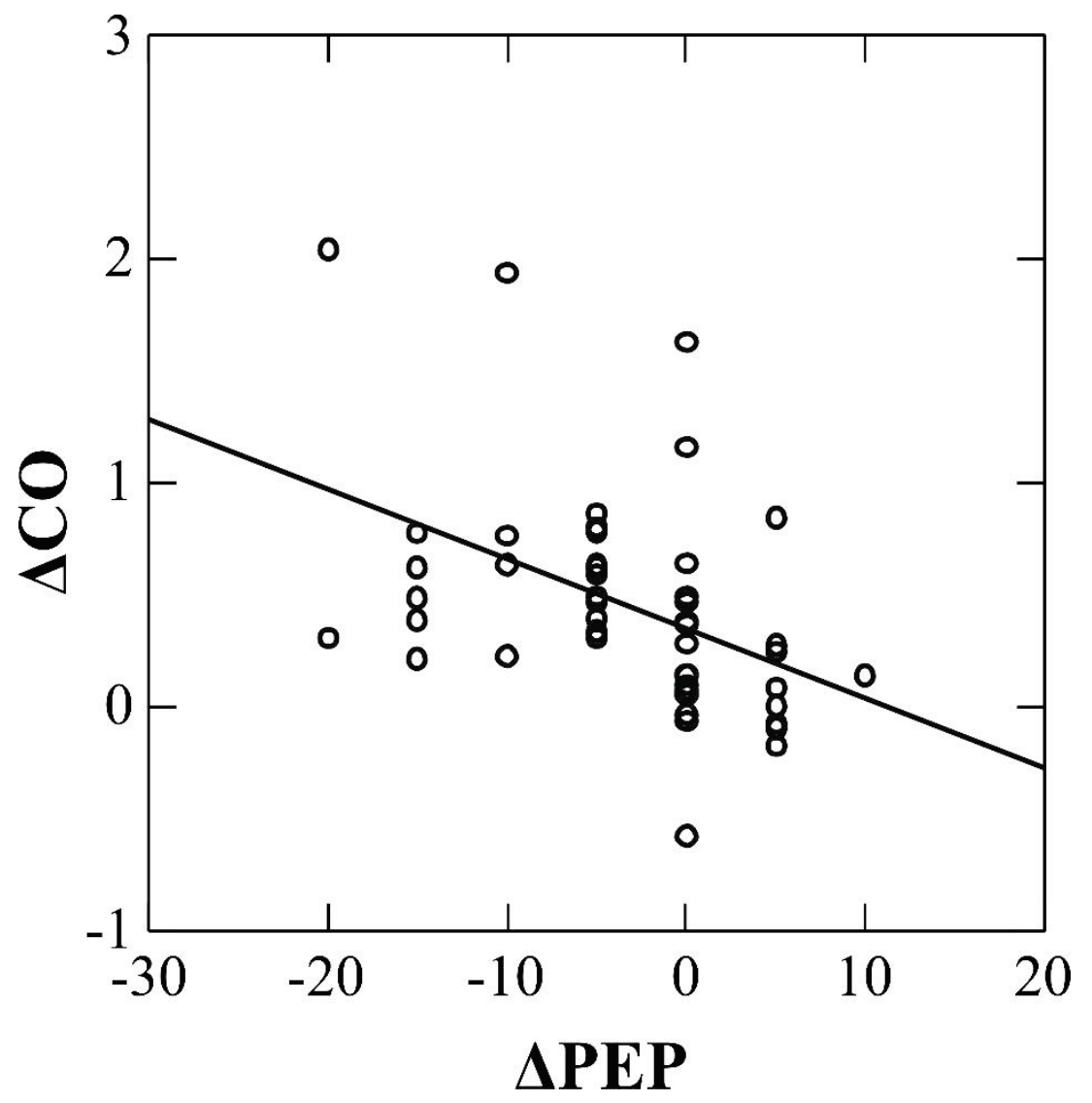

Fig. 5. Scatterplot between a change in

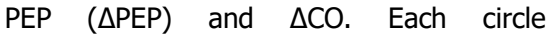
corresponds to one subject. In subjects with more expressed decrease in PEP (more negative $\triangle \mathrm{PEP}$ ), the higher increase in $\mathrm{CO}$ (higher $\triangle \mathrm{CO}$ ) was observed.

In the clinical or experimental settings where invasive measurement of basic cardiovascular measures is impractical non-invasive method of hemodynamic monitoring of the cardiovascular system on a beat-tobeat basis by ICG could be very useful (Peacock et al. 2000, Krzesiński et al. 2012, Parry et al. 2015). In previous studies, the validity of SV from ICG when assessing the changes in stroke volume was approved comparing its performance against invasive methods (thermodilution method, Fick method) during various conditions (Nieminen et al. 2000, Gujjar et al. 2008, McFetridge-Durdle et al. 2008, Burlingame et al. 2013, Kim et al. 2013). According to several validation studies, ICG was suggested as a reliable method to determine both the absolute value and changes of SV during different conditions (Yung et al. 2004, Brown et al. 2005, Schmidt et al. 2005). Although in some studies, the preciseness of ICG to estimate absolute values of stroke volume was challenged, its ability to monitor trends in SV and measures derived from it was approved (Blohm et al. 2014, Fellahi et al. 2014, Kim et al. 2013, Gujjar et al. 2008). TFC is an ICG derived measure providing information on the fluid content in the thorax. It was demonstrated that TFC is a reliable parameter for evaluating the hemodialysis and diuretics induced changes in preload (Zalewski et al. 2013, Sanidas et al. 2009, Graziani et al. 2008, van De Water et al. 2005, Peacock et al. 2000). As a limitation of this measure, the changes in diaphragm position may also cause changes to electrical pathways of transthoracic sensing currents (Zhang et al. 2016) introducing a potential error to TFC as a measure of preload in our study during HUT. Taken together, our study was focused on the analysis of the changes in cardiovascular measures rather than their absolute values - therefore we assume that the distortion of results introduced by the non-invasiveness of the applied measurement approaches was not substantial. 


\section{Conclusions}

We conclude that preejection period could be used as a sympathetic activity index in the conditions when the significant changes in preload, afterload or diastolic blood pressure do not occur. During various physiological and pathological states, the potential changes in other cardiovascular characteristics should be taken into consideration to properly interpret PEP changes.

\section{References}

AFONSO L, PRADHAN J, VEERANNA V, NIRAJ A, JACOB S: Global and regional left ventricular contractile impairment in patients with Wolff-Parkinson-White syndrome. Indian Pacing Electrophysiol J 9: 195-206, 2009.

BEAUCHAINE TP, GATZKE-KOPP L, NEUHAUS E, CHIPMAN J, REID MJ, WEBSTER-STRATTON C: Sympathetic- and parasympathetic-linked cardiac function and prediction of externalizing behavior, emotion regulation, and prosocial behavior among preschoolers treated for ADHD. J Consult Clin Psychol 81: 481-493, 2013.

BERNTSON GG, CACIOPPO JT, BINKLEY PF, UCHINO BN, QUIGLEY KS, FIELDSTONE A: Autonomic cardiac control. III. Psychological stress and cardiac response in autonomic space as revealed by pharmacological blockades. Psychophysiology 31: 599-608, 1994.

BETTENCOURT MJ, PINTO BG, DE OLIVEIRA EI, SILVA-CARVALHO L: Two anomalous cardiovascular responses to active standing in essential hypertension. Rev Port Cardiol 27: 613-621, 2008.

BLOHM ME, OBRECHT D, HARTWICH J, MUELLER GC, KERSTEN JF, WEIL J, SINGER D: Impedance cardiography (electrical velocimetry) and transthoracic echocardiography for non-invasive cardiac output monitoring in pediatric intensive care patients: a prospective single-center observational study. Crit Care 18: 603, 2014.

BOGERT LWJ, VAN LIESHOUT JJ: Non-invasive pulsatile arterial pressure and stroke volume changes from the human finger. Exp Physiol 90: 437-446, 2005.

BRIGNOLE M, ALBONI P, BENDITT D, BERGFELDT L, BLANC JJ, BLOCH THOMSEN PE, VAN DIJK JG, FITZPATRICK A, HOHNLOSER S, JANOUSEK J: Guidelines on management (diagnosis and treatment) of syncope. Eur Heart J 22: 1256-1306, 2001.

BROWN CV, SHOEMAKER WC, WO CC, CHAN L, DEMETRIADES D: Is noninvasive hemodynamic monitoring appropriate for the elderly critically injured patient? J Trauma 58: 102-107, 2005.

BUCH J, EGEBLAD H, HANSEN PB, KJAERGÅRD H, WALDORFF S, STEINESS E: Correlation between changes in systolic time intervals and left ventricular end-diastolic diameter after preload reduction. Non-invasive monitoring of pharmacological intervention. Br Heart J 44: 668-671, 1980.

BURLINGAME J, OHANA P, AARONOFF M, SETO T: Noninvasive cardiac monitoring in pregnancy: impedance cardiography versus echocardiography. J Perinatol 33: 675-680, 2013.

CACIOPPO JT, BERNSTON GG, BINKLEY PF, QUIGLEY KS, UCHINO BN, FIELDSTONE A: Autonomic cardiac control. II. Noninvasive indices and basal response as revealed by autonomic blockades. Psychophysiology 31: 586-598, 1994a.

CACIOPPO JT, UCHINO BN, BERNTSON GG: Individual differences in the autonomic origins of heart rate reactivity: the psychometrics of respiratory sinus arrhythmia and preejection period. Psychophysiology 31: 412-419, 1994b.

CARROLL D, HARRIS MG, CROSS G: Haemodynamic adjustments to mental stress in normotensives and subjects with mildly elevated blood pressure. Psychophysiology 28: 438-446, 1991. 
CHAN GS, MIDDLETON PM, CELLER BG, WANG L, LOVELL NH: Change in pulse transit time and pre-ejection period during head-up tilt-induced progressive central hypovolaemia. J Clin Monit Comput 21: 283-293, 2007.

CIESLAK M, RYAN WS, MACY A, KELSEY RM, CORNICK JE, VERKET M, BLASCOVICH J, GRAFTON S: Simultaneous acquisition of functional magnetic resonance images and impedance cardiography. Psychophysiology 52: 481-488, 2015.

CRITCHLEY LA, CONWAY F, ANDERSON PJ, TOMLINSON B, CRITCHLEY JA: Non-invasive continuous arterial pressure, heart rate and stroke volume measurements during graded head-up tilt in normal man. Clin Auton Res 7: 97-101, 1997.

EL-DAWLATLY A, MANSOUR E, AL-SHAER AA, AL-DOHAYAN A, SAMARKANDI A, ABDULKARIM A, ALSHEHRI H, FADEN A: Impedance cardiography: noninvasive assessment of hemodynamics and thoracic fluid content during bariatric surgery. Obes Surg 15: 655-658, 2005.

FAHRENBERG J, FOERSTER F: A multiparameter study in non-invasive cardiovascular assessment. J Psychophysiology 5: 145-158, 1991.

FELLAHI JL, FISCHER MO: Electrical bioimpedance cardiography: an old technology with new hopes for the future. J Cardiothorac Vasc Anesth 28: 755-760, 2014.

GARRARD CL, WEISSLER AM, DODGE HT: The relationship of alterations in systolic time intervals to ejection fraction in patients with cardiac disease. Circulation 42: 455-462, 1970.

GOEDHART AD, WILLEMSEN G, HOUTVEEN JH, BOOMSMA DI, DE GEUS EJC: Comparing low frequency heart rate variability and preejection period: two sides of a different coin. Psychophysiology 45: 1086-1090, 2008 .

GRAZIANI G, BADALAMENTI S, COMO G, AMBROSO G, GAZZANO G, FINAZZI S, MANGIAROTTI R, MORGANTI A: Validation study of thoracic fluid bioimpedance for assessing the haemodialysis-induced changes in total body fluids. Blood Purif 12: 106-112, 2008.

GUJJAR AR, MURALIDHAR K, BANAKAL S, GUPTA R, SATHYAPRABHA TN, JAIRAJ PS: Non-invasive cardiac output by transthoracic electrical bioimpedance in post-cardiac surgery patients: comparison with thermodilution method. J Clin Monit Comput 22: 175-180, 2008.

HARRELL JP, CLARK VR: Cardiac responses to psychological tasks: impedance cardiographic studies. Biol Psychol 20: 261-283, 1985.

HODGES GJ, MATTAR L, ZUJ KA, GREAVES DK, ARBEILlE PM, HUGHSON RL, SHOEMAKER JK: WISE-2005: prolongation of left ventricular pre-ejection period with 56 days head-down bed rest in women. Exp Physiol 95: 1081-1088, 2010.

HOUTVEEN JH, GROOT PF, GEUS EJ: Effects of variation in posture and respiration on RSA and pre-ejection period. Psychophysiology 42: 713-719, 2005.

IMHOLZ BP, WIELING W, VAN MONTFRANS GA, WESSELING KH: Fifteen years experience with finger arterial pressure monitoring: assessment of the technology. Cardiovasc Res 38: 605-616, 1998.

KANJWAL K, MASUDI S, GRUBB BP: Syncope in children and adolescents. Adolesc Med State Art Rev 26: 692-711, 2015.

KATZ AM: Physiology of The Heart. 5th Edition. Wolters Kluwer Health/Lippincott Williams \& Wilkins Health, Philadelphia, 2011, $306 \mathrm{p}$.

KELSEY RM, BLASCOVICH J, LEITTEN CL, SCHNEIDER TR, TOMAKA J, WIENS S: Cardiovascular reactivity and adaptation to recurrent psychological stress: the moderating effects of evaluative observation. Psychophysiology 37: 748-756, 2000.

KIM JY, KIM BR, LEE KH, KIM KW, KIM JH, LEE SI, KIM KT, CHOE WJ, PARK JS, KIM JW: Comparison of cardiac output derived from FloTrac/Vigileo and impedance cardiography during major abdominal surgery. $J$ Int Med Res 41: 1342-1349, 2013.

KRZESIŃSKI P, SADŁOŃ NM, GRUDZIEŃ KT, GIELERAK G, STAŃCZYK A: Impedance cardiography as a tool for haemodynamic monitoring at high altitude: a preliminary study. Kardiol Pol 70: 911-917, 2012.

KRZESIŃSKI P, STAŃCZYK A, GIELERAK G, PIOTROWICZ K: The hemodynamic patterns in hypertensive men and women of different age. J Hum Hypertens 30: 177-185, 2016. 
KUIPERS NT, SAUDER CL, CARTER JR., RAY CA: Neurovascular responses to mental stress in the supine and upright postures. $J$ Appl Physiol (1985) 104: 1129-1136, 2008.

LARKIN KT, KASPROWICZ AL: Validation of a simple method of assessing cardiac preejection period: a potential index of sympathetic nervous system activity. Percept Mot Skills 63: 295-302, 1986.

LASATER M, VON RUEDEN KT: Outpatient cardiovascular management utilizing impedance cardiography. $A A C N$ Clin Issues 14: 240-250, 2003.

LEWIS RP, LEIGHTON RF, FORESTER WF, WEISSLER AM: Systolic time intervals. In: Noninvasive Cardiology. New York: Grune \& Stratton, 1974, pp 301-368.

LEWIS RP, RITTOGERS SE, FROESTER WF, BOUDOULAS H: A critical review of the systolic time intervals. Circulation 56: 146-158, 1977.

LINDVALL K, KAHAN T, DE FAIRE U, OSTERGREN J, HJEMDAHL P: Stress-induced changes in blood pressure and left ventricular function in mild hypertension. Clin Cardiol 14: 125-132, 1991.

MCFETRIDGE-DURDLE JA, ROUTLEDGE FS, PARRY MJ, DEAN CR, TUCKER B: Ambulatory impedance cardiography in hypertension: a validation study. Eur J Cardiovasc Nurs 7: 204-213, 2008.

MENSAH-BROWN NA, WAKAI RT, CHEULKAR B, SRINIVASAN S, STRASBURGER JF: Assessment of left ventricular pre-ejection period in the fetus using simultaneous magnetocardiography and echocardiography. Fetal Diagn Ther 28: 167-174, 2010.

MEZZACAPPA ES, KELSEY RM, KATKIN ES: The effects of epinephrine administration on impedance cardiographic measures of cardiovascular function. Int J Psychophysiol 31: 189-196, 1999.

NEWLIN DB, LEVENSON RW: Pre-ejection period: measuring beta-adrenergic influences upon the heart. Psychophysiology 16: 546-553, 1979.

NIEMINEN T, KÖÖBI T, TURJANMAA V: Can stroke volume and cardiac output be determined reliably in a tilt-table test using the pulse contour method? Clin Physiol 20: 488-495, 2000.

OBEN J, TOMSIN K, MESENS T, STAELENS A, MOLENBERGHS G, GYSELAERS W: Maternal cardiovascular profiling in the first trimester of pregnancies complicated with gestation-induced hypertension or fetal growth retardation: a pilot study. J Matern Fetal Neonatal Med 27: 1646-1651, 2014.

OVADIA M, GEAR K, THOELE D, MARCUS FI: Accelerometer systolic time intervals as fast-response sensors of upright posture in the young. Circulation 92: 1849-1859, 1995.

PACKER M, ABRAHAM WT, MEHRA MR, YANCY CW, LAWLESS CE, MITCHELL JE, SMART FW, BIJOU R, O'CONNOR CM, MASSIE BM: Utility of impedance cardiography for the identification of short-term risk of clinical decompensation in stable patients with chronic heart failure. J Am Coll Cardiol 47: 2245-2252, 2006.

PARRY M, NIELSON CA, MUCKLE F, O'KEEFE-MCCARTHY S, VAN LIEN R, MEIJER JH: A novel noninvasive device to assess sympathetic nervous system function in patients with heart failure. Nurs Res 64: 351-360, 2015.

PEACOCK WF, ALBERT NM, KIES P, WHITE RD, EMERMAN CL: Bioimpedance monitoring: better than chest $\mathrm{X}$-ray for predicting abnormal pulmonary fluid? Congest Heart Fail 6: 86-89, 2000.

RICHTER M, GENDOLLA GH: The heart contracts to reward: monetary incentives and preejection period. Psychophysiology 46: 451-457, 2009.

SANIDAS EA, GRAMMATIKOPOULOS K, ANASTASIADIS G, PAPADOPOULOS D, DASKALAKI M, VOTTEAS V: Thoracic fluid content and impedance cardiography: a novel and promising noninvasive method for assessing the hemodynamic effects of diuretics in hypertensive patients. Hellenic J Cardiol 50: 465-471, 2009.

SCHÄCHINGER H, WEINBACHER M, KISS A, RITZ R, LANGEWITZ W: Cardiovascular indices of peripheral and central sympathetic activation. Psychosom Med 63: 788-796, 2001.

SCHMIDT C, THEILMEIER G, VAN AKEN H, KORSMEIER P, WIRTZ SP, BERENDES E, HOFFMEIER A, MEISSNER A: Comparison of electrical velocimetry and transoesophageal Doppler echocardiography for measuring stroke volume and cardiac output. Br J Anaesth 95: 603-610, 2005.

SCHNEIDER GM, JACOBS DW, GEVIRTZ RN, O'CONNOR DT: Cardiovascular haemodynamic response to repeated mental stress in normotensive subjects at genetic risk of hypertension: evidence of enhanced reactivity, blunted adaptation, and delayed recovery. J Hum Hypertens 17: 829-840, 2003. 
SHERWOOD A, ALLEN MT, FAHRENBERG J, KELSEY RM, LOVALlO WR, VAN DOORNEN LJ: Methodological guidelines for impedance cardiography. Psychophysiology 27: 1-23, 1990.

SODOLSKI T, KUTARSKI A: Impedance cardiography: A valuable method of evaluating haemodynamic parameters. Cardiol J 14: 115-126, 2007.

STAFFORD RW, HARRIS WS, WEISSLER AM: Left ventricular systolic time intervals as indices of postural circulatory stress in man. Circulation 41: 485-492, 1970.

SVACINOVA J, JAVORKA M, NOVAKOVA Z, ZAVODNA E, CZIPPELOVA B, HONZIKOVA N: Development of causal interactions between systolic blood pressure and inter-beat intervals in adolescents. Phys Res 64: 821-829, 2015.

VAN DE WATER JM, MOUNT BE, CHANDRA KM, MITCHELL BP, WOODRUFF TA, DALTON ML: TFC (thoracic fluid content): a new parameter for assessment of changes in chest fluid volume. Am Surg 71: 81-86, 2005.

VAN LIEN R, SCHUTTE NM, MEIJER JH, DE GEUS EJ: Estimated preejection period (PEP) based on the detection of the R-wave and dZ/dt-min peaks does not adequately reflect the actual PEP across a wide range of laboratory and ambulatory conditions. Int J Psychophysiol 87: 60-69, 2013.

WIDJAJA D, MONTALTO A, VLEMINCX E, MARINAZZO D, VAN HUFFEL S, FAES L: Cardiorespiratory information dynamics during mental arithmetic and sustained attention. PLoS One 10: e0129112, 2015.

XIAJUAN Z, DING D, YANYAN H, ZHEN H: Impedance cardiographic hemodynamic variables and hypertension in elderly Han residents. Ups J Med Sci 118: 80-86, 2013.

YUNG GL, FEDULLO PF, KINNINGER K, JOHNSON W, CHANNICK RN: Comparison of impedance cardiography to direct Fick and thermodilution cardiac output determination in pulmonary arterial hypertension. Congest Heart Fail 10 (2 Suppl 2): 7-10, 2004.

ZALEWSKI P, JONES D, LEWIS I, FRITH J, NEWTON JL: Reduced thoracic fluid content in early-stage primary biliary cirrhosis that associates with impaired cardiac inotropy. Am J Physiol Gastrointest Liver Physiol 305: G393-G397, 2013.

ZHANG J, CRITCHLEY LA, LEE DC, KHAW KS, LEE SW: The effect of head up tilting on bioreactance cardiac output and stroke volume readings using suprasternal transcutaneous Doppler as a control in healthy young adults. J Clin Monit Comput 30: 519-526, 2016. 